\title{
UMA VISITA ÀS ONDAS DO MOVIMENTO FEMINISTA ATRAVÉS DA ANÁLISE DOS CONTOS “THE YELLOW WALLPAPER” E "WOMAN HOLLERING CREEK”
}

\author{
VISITING THE WAVES OF FEMINIST MOVEMENT THROUGH THE READING OF \\ TWO SHORT STORIES: “THE YELLOW WALLPAPER” AND "WOMAN HOLLERING CREEK”
}

\section{RESUMO}

O campo dos estudos culturais/literários foca na identificação dos fenômenos responsáveis pela marginalização/subalternização dos sujeitos. Assim, a análise das ondas do movimento feminista através dos olhos da literatura torna possível uma maior aproximação da sociedade perante os fatos que ocorreram e ocorrem no mundo, no intuito de que a luta contra a desigualdade e o patriarcalismo perpetue-se e tornase uma realidade cada vez mais tangível. O objetivo deste artigo é contextualizar as ondas feministas através da análise de dois contos: "The Yellow Wallpaper" da autora Charlotte Perkins Gilman, publicado originalmente em 1892 e "Woman Hollering Creek" da escritora Sandra Cisneros, publicado em 1991. Para isso, fundamentamos esta pesquisa principalmente com os trabalhos de Pinto (2010), Devereux (2014), Anzaldua (1987), Bittencourt (2015), Walter (2015) e Saffioti (1986) e percebemos que os quase 100 anos que separam as duas histórias foram marcados por diversas conquistas da agenda feminista. Através das ondas se tornou possível didatizar o estudo do movimento contra a opressão vivida pelas mulheres e situar a literatura como um meio para ilustrar esse percurso. Uma vez que "The Yellow Wallpaper" e "Woman Hollering Creek" representam bem os dois momentos e discursos da primeira e terceira ondas respectivamente.

Palavras-chave: Ondas Feministas; Patriarcalismo; Literatura; Sandra Cisneros; Charlotte Gilman.

\begin{abstract}
The field of cultural/literary studies focuses on the identification of the phenomena responsible for the marginalization / subalternization of the subjects. Thus, the analysis of the waves of the feminist movement through the eyes of literature makes possible a greater approximation of society to the facts that have occurred and occur in the world, in order that the fight against inequality and patriarchalism perpetuate and become an increasingly tangible reality. It is the purpose of this article to contextualize the feminist waves through the analysis of two stories: "The Yellow

Larissa de Pinho Cavalcanti

Doutora em Linguística pela Universidade Federal de Pernambuco (2017).

E-mail: laracvanti@gmail.com

Rafaela Albuquerque Gonçalves

Especialista em Língua e Literatura Inglesa (FAFIRE) e mestranda em Letras pela Universidade Federal de Pernambuco. E-mail: rafa_buquerque@hotmail.com
\end{abstract}


Wallpaper" by author Charlotte Perkins Gilman, originally published in 1892 and "Woman Hollering Creek" by Sandra Cisneros, published in 1991. For this, we base this research mainly on the works of Pinto (2010), Devereux (2014), Anzaldua (1987), Bittencourt (2015), Walter (2015) and Saffioti (1986) and we realize that the almost 100 years that separate the two histories were marked by various achievements of the feminist agenda. Through the waves it became possible to study systematically the movement against oppression experienced by women and to situate literature as means of illustrating this path. Since "The Yellow Wallpaper" and "Woman Hollering Creek" well represent the two moments and speeches of the first and third waves respectively.

Keywords: Feminist Waves; Patriarchy; Literature; Sandra Cisneros; Charlotte Gilman.

\section{INTRODUÇÃO}

O feminismo é um movimento bastante peculiar, no sentido de que cria, através de suas ações, tanto mudanças sociais quanto teorias acadêmicas. É um campo que não se encerra em si mesmo e que, para estudá-lo, é necessário que se faça uma associação entre a história da luta da mulher na sociedade com suas produções teóricas feministas. Isso para que se esboce um quadro da situação atual de sua luta.

Contudo, não é possível conceber uma linearidade de pesquisa nesse campo, uma vez que não se fala em um feminismo universal, mas em diversos feminismos (NEGRÃO, 2002). Dessa forma, pode-se dizer que não há uma única história feminista, ainda que, do ponto de vista histórico, consigamos diferenciar períodos por características dominantes. Compreender como essas diferentes correntes surgiram e se articularam nos propicia uma contextualização do movimento em função de seus ideais e das ideologias que mudaram de uma época para outra, uma vez que os períodos históricos e as necessidades sociais e políticas mudam de acordo com a vivência feminina, dividem-se as fases do movimento em três ondas (COSTA, 2002). Além disso, na relação entre produção cultural/literária e feminismo, entender como as ondas do movimento se organizam historicamente abre espaço para o diálogo entre representações da mulher, dos ideais de mulher e do próprio feminismo na literatura.

Dessa forma, vale compreender que a história tradicional do feminismo organiza seus diferentes movimentos em três ondas (hoje, já se fala em uma quarta onda). A primeira delas diz respeito ao surgimento do próprio movimento com a luta das mulheres, no seio da Revolução Francesa, por seus direitos civis, ainda exclusivos aos homens. Nesse período, que se estende à luta sufragista, direitos civis básicos são o ponto fundamental da agenda feminista. Era uma luta contra a discriminação de base trabalhista e uma denúncia a opressão vivida devido ao sistema patriarcal.

A segunda onda, por sua vez, começa na década de 1960, com especial ênfase nos Estados Unidos e França, que logo sustentariam pensamentos divergentes. 
Enquanto as primeiras denunciavam a opressão masculina e queriam a igualdade dos gêneros, as francesas queriam ser valorizadas pelas diferenças entre homens e mulheres, dando ênfase às especificidades das mulheres. É nesse período que "introduz-se, assim, a noção de equidade e paridade no debate igualdade-diferença dentro dos movimentos feministas” (NARVAZ; KOLLER, 2006, p. 649). É pertinente à essa onda a distinção entre sexo e gênero e a famosa frase de Simone de Beauvoir (1980. p. 9): "não se nasce mulher, torna-se mulher" é uma das grandes contribuições que melhor retratam as conquistas da segunda onda do movimento feminista.

E com essa primeira noção de diferença se inicia a terceira onda, uma vez que é percebido que as teorias formuladas até o momento perpetuavam a necessidade e a voz de mulheres brancas de classe média-alta e não a totalidade feminina, um universo marcado por grandes diferenças: as mulheres negras, lésbicas, indígenas etc. Ou seja, passa-se a perceber as diferenças intragênero, entre as próprias mulheres e a reconhecer os diferentes locais sociais como originadores de lutas e identidades feministas distintas.

Embora essa seja a história tradicionalmente vinculada ao feminismo angloamericano, Hemmings (2009) argumenta que é preciso um olhar crítico para essa narrativa do feminismo. De acordo com a autora, essa narrativa didatizada simplifica a construção do pensamento feminista e a natureza de seus próprios debates ao longo da história, fixando autoras e perspectivas em décadas específicas em decorrência de uma leitura do passado sob o viés da teoria pós-estruturalista, compreendido como o primeiro a questionar a universalização do conceito de "mulher" e do significado de suas experiências e lutas.

Sem desfazer o valor de uma didatização para estudos introdutórios ou para principiantes no feminismo acadêmico, concordamos com Hemmings (2009) que manter essa visão homogênea sobre um movimento político e social tão diverso é defender uma inocência incongruente com a leitura da realidade. Outrossim, nos alinhamos a Schneider (2009) em sua defesa da pouca estabilidade e homogeneidade nas discussões históricas do feminismo. Reconhecemos a importância da ressalva desta autora, que concorda com Hemmings de que a própria década de 1970, “já previa o olhar preconceituoso sobre a mulher diferente - a lésbica, a analfabeta, a pobre, a não branca, a discriminada em qualquer termo" (SCHEINDER, 2009, p. 254).

Pensando no propósito de nosso artigo, devemos destacar, também, a crítica de Hemmings (2009) e Schneider (2009) com relação ao ocultamento da década de 1980 como uma mera ponte entre uma década essencialista e a década de 1990, caracterizada pela emergência da diferença/diversidade. Concordamos com essas autoras na necessidade de reconhecer que a organização do feminismo racialmente marcado já começara na década de 1980 (a exemplo do próprio feminismo chicano e afrodescendente nos Estados Unidos), mas que seus discursos apenas se popularizariam na década de 1990, com o vigor das teorias pós-estruturalistas e póscoloniais. Com isso, evita-se obscurecer o trabalho intelectual e as conquistas sociais de uma década e das mulheres que nela viveram, lutaram e produziram. 
A partir desse percurso histórico, retomamos o objetivo desse artigo de contextualizar as ondas feministas através da análise de dois contos: "The Yellow Wallpaper" da autora Charlotte Perkins Gilman, publicado originalmente em 1892, e "Woman Hollering Creek" da escritora Sandra Cisneros, publicado em 1991. Escolhemos essas duas histórias, pois acreditamos que ambas representem bem os dois momentos e discursos da primeira e terceira ondas respectivamente. A seguir, fazemos um diálogo entre as condições sócio-históricas, de modo mais detalhado, e a própria obra literária.

\section{PRIMEIRA ONDA E “THE YELLOW WALLPAPER”}

Do ponto de vista histórico, a primeira onda do movimento feminista teve início na Revolução Francesa, contudo, sabe-se que a luta da mulher contra a dominação masculina e a sociedade patriarcal sempre reverberou "no silêncio da história e foram apagadas e esquecidas pela voz grave dos dominantes" (BITTENCOURT, 2015, p. 199). Dessa forma não podemos afirmar que foi a partir da Revolução Francesa que as mulheres acordaram para sua situação, contudo, por falta de documentos históricos precisos, o movimento data seu início a partir deste ponto.

Do final do século XVIII até as primeiras décadas do século XX se caracteriza a primeira onda feminista, período que compreende a publicação do conto de Gilman e que coloca a luta pelo sufrágio universal como ponto central de reinvindicação. A ideia do movimento nessa fase é a de:

Ampliar o que se entende por democracia, tornando iguais perante a lei os crescentes contingentes humanos das sociedades competitivas. Nesta concepção, cabe reivindicar para as mulheres igualdade de direitos com relação aos homens no plano de jure (SAFFIOTI, 1986, p. 107).

Nesse período também se caracteriza o cenário de guerra mundial, em que homens deixam seus cargos para ir às batalhas, abrindo espaço para as mulheres no ambiente de trabalho. Assim, a reinvindicação de direitos passa a incluir na agenda à introdução da mulher na composição da renda familiar, como também o acesso a universidades. Contudo, essas duas últimas pautas ficam ainda um pouco à margem do movimento devido à questão sufragista.

É na primeira onda do movimento feminista que a dominação masculina rege a sociedade com mais rigor, uma vez que não havia uma organização entre as mulheres para se lutar contra o patriarcalismo. A instituição do casamento e o poder dos maridos sobre suas esposas ditava o cenário social em que Charlotte Gilman, autora do conto "The Yellow Wallpaper" estava envolvida e no conto temos oportunidade de refletir sobre a tirania do laço conjugal sobre a estabilidade e independência psíquica e física da mulher. 
Gostaríamos de salientar, entretanto, que embora a história não aborde diretamente a questão do trabalho e do voto femininos, principal agenda do movimento feminista desse período; indiretamente ao colocar que a personagem está paralisada e improdutiva, subentende-se a existência desta problemática. Pois, o foco da narrativa de Gilman nesse momento é o de retratar a esfera doméstica e as relações entre os sexos, principalmente no lar e no casamento.

Charlotte Perkins Gilman publica o conto “The Yellow Wallpaper” em 1892, e nos apresenta a uma personagem refém de um marido médico que usa de sua posição para controlar o estado físico e mental de sua esposa. Através da narrativa, Gilman representa a dita superioridade masculina sobre a feminina, bem como construções sociais relacionadas a isso, como a questão da fragilidade do corpo e da mente da mulher que tanto contribuiu na época para a manutenção do sistema patriarcal e ainda hoje, contribui.

Assim como a personagem do conto, a autora não se adaptou à vida de casada e passou por uma fase de tratamento contra histeria. Gilman procurou na época um “especialista em nervos", o Dr. S. Weir Mitchell, e ao que tudo indica foi o período que ela passou em tratamento que a inspirou a escrever a história, pois o aclamado doutor passou-lhe como prescrição médica dedicar-se ao trabalho doméstico e à filha e dizendo à autora: "nunca toque uma caneta, lápis ou pincel enquanto viver ${ }^{1}$ " (GILMAN, 1935, p. 5).

No conto, o esposo da personagem prescreve descanso e isolamento, a chama de "tolinha" por discordar de sua palavra e controla cada passo do seu dia. E apesar da história dar a entender que o marido de fato ama sua mulher, até o amor é utilizado como forma de repressão. Pois, ao julgar-se superior à figura feminina, por sua posição e conhecimento, não dá voz aos sentimentos de sua esposa angustiada. Assim, ficção e realidade, misturam-se e nos fazem perceber claramente que a ciência da época se utilizava da histeria como argumento de controle social para mulheres.

Historicamente ligada à feminilidade por centenas de anos, a histeria e seus sintomas involuntários, incontroláveis e somáticos estavam chegando a ser entendidos no emergente discurso feminista crítico não como uma condição médica, mas sim, cultural, um índice incorporado de formas de opressão ${ }^{2}$ (DEVEREUX, 2014, p. 20).

Dessa forma, o relato da mulher nunca nomeada no conto é a forma que Gilman encontrou de denunciar à sociedade o que estava acontecendo. John, o personagem do marido leva à esposa, que antes era sã, à loucura. Sem ninguém para conversar,

\footnotetext{
1 "Never touch pen, brush or pencil as long as you live" (GILMAN, 1935, p. 5). Tradução Nossa.

2 "Historically linked with femininity for hundreds of years, hysteria's involuntary, uncontrollable, somatic symptoms were coming to be understood in the emerging critical feminist discourse not as a medical condition but a cultural one, an embodied index of forms of oppression" (DEVEREUX, 2014, p. 20). Tradução Nossa.
} 
sem nunca ser atendida e privada do seu lazer de escrever, a personagem passa a ter visões de mulheres encarceradas em um papel de parede amarelo desgastado, com pedaços faltando, os quais a própria arrancou, como forma de interação com o meio que a cercava.

O cárcere e a anonimato da protagonista, bem como suas visões, servem para ilustrar que esse não era somente um caso isolado, pois ao optar por não nomear a personagem principal, ela passa a simbolizar a situação feminina como um todo. $\mathrm{Ou}$ seja, as mulheres encarceradas e a que foi levada à loucura representam a vivência da mulher no período da Primeira Onda feminista: sempre reprimidas e submetidas ao patriarcalismo. Pois, a personagem assume que os pedaços retirados, fazem parte das inúmeras tentativas daquelas mulheres de escaparem. Assim, o final trágico nos mostra como um casamento pode representar uma prisão e de como todas as mulheres possuem seus próprios papéis de parede amarelo e de como é difícil (ou até mesmo impossível, como retrata a narrativa) conseguir transcende-los.

O conto denuncia o controle masculino na instituição do casamento de acordo com as instituições sociais do seu contexto de escrita. Pois, até a medicina da época corroborava com o uso de diagnósticos de histeria para manter as mulheres sobre seu domínio. Então a partir desta denúncia de Gilman, como também da larga influência da Revolução Francesa, deu-se início a primeira onda feminista. Ou seja, chegou-se um ponto em que as vozes femininas não poderiam mais ser silenciadas.

\section{2 "WOMAN HOLLERING CREEK E A TERCEIRA ONDA FEMINISTA}

Depois das conquistas da primeira fase do movimento, houve um período de calmaria nas reinvindicações. Contudo, com o retorno masculino em massa devido ao fim das guerras, as mulheres foram novamente empurradas para dentro de casa, na expectativa de satisfação com devoção e obediência aos maridos e filhos. A mídia da época inclusive reforçava essa imagem para obter o controle sobre o feminino através da naturalização de tais papéis (ALVES; PITANGUY, 1985).

Então depois de terem experimentado uma forma de independência no período de guerras, as mulheres começaram a questionar-se sobre o que era dito e exposto tão massivamente na mídia. Assim, começam a se organizar na retomada do movimento: buscando maior representação na vida política, o ingresso definitivo no mercado de trabalho com condições de igualdade salarial, o ingresso às universidades etc.

A segunda onda, portanto, compreende o período entre as décadas de 1960 e 1980 num avanço de percepção e análise do movimento como um todo, incorporando diversas frentes de luta e denunciando o patriarcado como forma de expressão do poder político exercido através da dominação masculina e inferiorização das mulheres que ultrapassa o campo do privado, invade todos os espaços da sociedade e representa uma estrutura de poder 
baseada tanto na violência quanto na ideologia (BITTENCOURT, 2015, p. 201).

Desse momento em diante, a luta feminina não cessou. Apenas aumentou e expandiu seus horizontes, uma vez que mulheres que ainda não viam suas demandas atendidas pela agenda feminista iniciaram seus próprios movimentos. Assim, surgem as correntes do feminismo negro, indígena, chicano entre outros. Introduzindo o começo da terceira onda.

No início da década de 9o, muitos grupos femininos sentem que não estão sendo representados pelo feminismo majoritariamente branco de classe média, uma vez que percebem que certas necessidades são diferentes entre as próprias mulheres. Assim, podemos dizer que a terceira onda surge com a proposta de "concentra-se na análise das diferenças, da alteridade, da diversidade e da produção discursiva da subjetividade. Com isso, desloca-se o campo do estudo sobre as mulheres e sobre os sexos para o estudo das relações de gênero" (NARVAZ; KOLLER, 2006, p. 649).

É nesse contexto que se enquadra a literatura feminista chicana. Uma forma de representação de uma minoria que deseja seu espaço e que possui características únicas e necessidades específicas. Esse grupo de mulheres vive uma tripla pressão social: da cultura mexicana originária; da cultura americana de vivência; e de gênero. É, então, por essa situação de alta vulnerabilidade que buscamos analisar como a literatura representa a realidade dessas pessoas e a obra da autora Sandra Cisneros mostrou-se um promissor objeto de estudo, uma vez que sua narrativa debate questões de fronteira, entrelugar, gênero, raça e etnia. Questões estas que colocam a identidade dos sujeitos migrantes de forma a problematizar a mulher no seu contexto latino-americano, favorecendo a discussão sobre esse grupo que é muitas vezes silenciado por uma ideologia dominante.

Por ser também chicana, a escritora incorpora em seus textos muito da sua experiência de vida:

Eu tenho escrito e falado muito sobre isto - quando nós participávamos de um seminário, e eu fiquei tão intimidada quando falamos sobre casas e me dei conta de que não tinha uma casa [própria] como meus colegas de classe. Mas em vez disto me levar a fugir da sala e interromper minha graduação por pânico, porque eu era uma pessoa da classe trabalhadora com muitos colegas de classes privilegiadas, isto me enraiveceu e me levou a escrever a partir do lugar da diferença. Agora eu percebo que este lugar de diferença é o meu dom (CISNEROS, 2002, p. 109)³.

3"I've been writing and talking about it a lot - when we were attending a seminar, and I was so intimidated when we talked about homes and realized that I did not have a [my] home like my classmates. But instead of leading me to flee the room and interrupt my graduation through panic, because I was a working class 
Assim, a autora apresenta um sensível ponto de vista sobre a problemática do não pertencimento, uma vez que suas personagens apresentam conflitos identitários e culturais por não se caracterizarem nem puramente mexicanas, nem americanas, ou seja, falam a partir do contexto chicano. Tal aspecto dentro da lógica do "fenômeno da globalização" e da modernidade tardia torna-se cada vez mais comum em muitos povos, principalmente devido ao atual fluxo migratório de imigrantes que buscam reconstruir suas vidas longe da crescente violência.

No conto "Woman Hollering Creek" somos apresentados a Cléofilas, uma mulher sonhadora que desde sua infância tem os paradigmas da sociedade patriarcal colocados como ponto central na sua vida. As mulheres que a cercam, as telenovelas mexicanas de que tanto gosta, reforçam o papel de esposa e mãe, além da mensagem de que, para se apaixonar, deve-se sofrer por amor: "Porque sofrer de amor é bom. Toda a dor torna-se doce. No final”4 (CISNEROS, 1992, p. 45).

Kafka argumenta que os exemplos dados pelas matriarcas servem para inscrever na mente das jovens mulheres a noção de diferença e inferioridade feminina, com o objetivo de reforçar a obediência e submissão como modelos ideais (KAFKA, 2008). Assim, mesmo após casar-se e mudar-se para os Estados Unidos com o marido, Cisneros coloca novamente na vida da personagem principal, duas vizinhas Dolores e Soledad que vivem para chorar pelos maridos e filhos perdidos, sempre aconselhando Cléofilas a nunca afastar-se de casa, a zelar pelo seu esposo e filho.

Contudo, mesmo com esses ideais em mente, a personagem encontra uma fissura no conto de fadas dito nas novelas mexicanas: acreditando que deve sofrer por amor, ela releva diversas surras dadas pelo marido, a infelicidade no campo matrimonial, a solidão por morar em um país estrangeiro falando somente espanhol etc. Até o momento em que decide que essa não é mais a vida que deseja para si mesma.

Ocorre o que Anzaldua (1987) chama de "estado de Coatlicue", que seria o momento que você descobre a si mesma, o estado em que você torna-se consciente de si mesma. Em suas palavras: "Conhecimento me faz mais sábia, me torna mais consciente. O Conhecimento é doloroso, porque depois que ele acontece, eu não posso ficar no mesmo lugar e me sentir confortável. Eu não sou mais a mesma pessoa que eu era5" (ANZALDUA, 1987, p. 70).

A partir desse ponto, em que Cléofilas entra no estado que poderíamos ligar ao de Coatlicue (ANZALDUA, 1987) é que ela começa a procurar por uma saída. $\mathrm{Na}$ consulta médica em que descobre estar mais uma vez grávida, a médica que a

person with many privileged classmates, this enraged me and led me to write from the place of difference. Now I realize that this place of difference is my gift" (CISNEROS, 2002, p.109). Tradução Nossa.

4 "Because to suffer for love is good. The pain all sweet somehow. In the end" (CISNEROS, 1992, p. 45). Tradução Nossa.

5 "Knowledge makes me more aware, it makes me more conscious. Knowing is painful because after it happens I can't stay in the same place and be comfortable. I am no longer the same person I was before." (ANZALDUA, 1987, p. 70). Tradução Nossa. 
examina oferece o modo de escape que tanto deseja: uma de suas colegas lhe dará uma carona até a fronteira, onde ela e seu filho poderão voltar para casa de seu pai. $\mathrm{O}$ retorno à segurança e ao aconchego é ao mesmo tempo desejado e temido. Desejado por representar o fim da situação traumática; temido, pela interpretação social que sua família e seus antigos amigos poderiam lhe atribuir.

Às vezes ela pensa na casa do seu pai. Mas como ela poderia voltar para lá? Seria uma desgraça. O que os vizinhos iriam falar? Chegando em casa daquela forma com um bebê no colo e outro para chegar. Onde estaria seu marido? (CISNEROS, 1992, p. 50) ${ }^{6}$.

É o medo natural da sua cultura de origem condená-la, contudo, sua situação como mulher e vítima de um casamento brutal sobressai-se em seu desespero. Para Madella, a violência do marido de Cléofilas é também uma questão cultural:

Os chicanos, na fronteira, são frequentemente violentos, não permitem que suas mulheres sejam independentes em nenhum caso, nem econômica nem emocionalmente. Essa violência, seja qual for, não é uma necessidade essencialista; Em vez disso, é uma construção social. Uma vez que os chicanos perderam sua capacidade de proteger e nutrir suas famílias (porque eles têm empregos baixos, sofrem violência psicológica, não podem se expressar linguisticamente muito bem e tantos outros motivos), a maneira como eles mostram seu poder é girando sua ira e humilhação contra alguém com quem eles têm controle, neste caso, suas esposas ${ }^{7}$ (MADELLA, 2014, p. 97).

Assim, podemos ver que as mulheres chicanas possuem sua própria agenda no âmbito do feminismo: a questão da fronteira, do preconceito de gênero, das pressões culturais etc. Reforçando o paradigma da terceira onda do movimento. No conto "Woman Hollering Creek", a personagem que fornece carona à Cléofilas representa o mito de "La llorona", que, nas palavras de Cisneros, converte-se em "La gritona".

"La Llorona” é uma história na cultura mexicana que representa as mulheres que se arrependem de transgredir as normas, ou seja, se arrependem por tentar quebrar o ciclo patriarcal. Sandoval (2008) coloca que a mulher do mito é vista como

6 Sometimes she thinks of her father's house. But how could she go back there? What a disgrace. What would the neighbors say? Coming home like that with one baby on her hip and one in the oven. Where's your husband? (CISNEROS, 1992, p. 50). Tradução Nossa.

7 "The Chicanos, in the borderland, the macho, is frequently violent, do not allow their women to be independent in any instance, either economically nor emotionally. This violence, whatsoever, is not an essentialist necessity; rather it is a social construction. Once the Chicanos have lost their capacity of protecting and nurturing their families (because they have low-jobs, suffer psychological violence, cannot express themselves linguistically very well, and so many other reasons), the way they find to show their power is by turning their anger and humiliation against someone over with they have control, in this case, their wives” (MADELLA, 2014, p. 97). Tradução Nossa. 
impotente, sem voz, fraca. E ela representa Cléofilas no começo do conto até que a personagem percebe que ela não é mais impotente, nem fraca, transformando-se assim em "La gritona”, uma mulher poderosa e com voz.

\section{CONSIDERAÇÕES FINAIS}

Com quase 100 anos separando as duas histórias, podemos perceber que a agenda feminista realizou diversas conquistas, contudo, infelizmente ainda há uma grande perpetuação do patriarcado em nossa sociedade. Através das ondas feministas se torna possível materializar, de certa forma, a opressão vivida pelas mulheres e a literatura consegue ilustrar de forma clara esse percurso.

Durante a primeira onda feminista, Charlotte Perkins Gilman com "The Yellow Wallpaper" representou uma mulher levada à loucura devido à pressão social de um casamento sufocante. Vale destacar também que Kate Chopin, em seu livro The Awakening mata sua personagem principal por afogamento, demonstrando que, naquela época, quase não havia um final feliz, ou uma saída satisfatória para as mulheres. A produção literária feminina, de forma majoritária, ilustrava o sentimento de sufocamento culminante da vida na sociedade da época. Na terceira onda, embora o sentimento ainda persista, nós somos apresentadas a alternativas na literatura e na vida real. O que demonstra a evolução da luta feminista em relação ao ganho da liberdade. Contudo, a sociedade ideal do ponto de vista feminino, ainda está longe de ser alcançada.

A crítica cultural presente nos estudos literários com os quais nos alinhamos propõe uma análise etnocêntrica e de gênero, que foca na identificação dos fenômenos responsáveis pela marginalização/subalternização dos sujeitos. Uma vez que a literatura mostra-se associada ao sentimento em forma de palavras, para elucidar de modo profundo a experiência humana, o ser/estar no mundo. Tomando como princípio o conceito de "leitor implícito" proposto por Iser (1974), sabemos que o texto provoca reações no leitor e é nesse fato que reside à ética literária e sua habilidade de "provocar ideações de (outras) identidades e outros mundos; (...), constituindo encruzilhadas imaginativas onde é possível avaliar as nossas escolhas" (WALTER, 2015). Assim, ao analisarmos o fenômeno das ondas do movimento feminista à luz da literatura com os contos por nós selecionados, tornamos possível uma maior provocação no/a leitor/a para que a luta contra a desigualdade e o patriarcalismo perpetue-se e torna-se uma realidade cada vez mais tangível, dentro e fora do mundo literário. 


\section{REFERÊNCIAS}

ALVES, Branca Moreira, PITANGUY, Jacqueline. O que é Feminismo? São Paulo: Ed. Abril cultural; Brasiliense, 1985.

ANZALDÚA, Gloria. Borderlands/La Frontera: the new mestiza. San Francisco: Aunt Lute Books, 1987.

BEAUVOIR, Simone de. O Segundo Sexo, v. I, II. Tradução Sérgio Milliet. Rio de Janeiro: Nova Fronteira, 1980.

BITTENCOURT, Naiara Andreoli. Movimentos Feministas. Insurgência, Brasília, v. 1, n. 1, p.198-210, jan. 2015. Semestral. Disponível em: http://periodicos.unb.br/index. php/insurgencia/article/viewFile/16758/11894. Acesso em: 19 dez. 2017.

CISNEROS, Sandra. Woman Hollering Creek and other stories. New York: Vintage Contemporaries, 1991.

COSTA, Claudia de Lima. O sujeito no feminismo: revisitando os debates. Cadernos Pagu, 19, 59-90, 2002.

DEVEREUX, Cecily. Hysteria, Feminism, and Gender Revisited: The Case of the Second Wave. English Studies in Canada, Edmonton, v. 40, n. 1, p.19-45, mar. 2014. Disponível em: https://journals.library.ualberta.ca/esc/index.php/ESC/article/ view/24855/18313. Acesso em: 19 dez. 2017.

GILMAN, Charlotte Perkins. The living of Charlotte Perkins Gilman: an autobiography. New York \& London: Appleton-Century, 1935.

. O papel de parede amarelo. 3. ed. Rio de Janeiro: José Olympio, 2017.

HEMMINGS, Clare. Contando estórias feministas. Revista Estudos Feministas, v. 17, n. 1, 2009.

KAFKA, Phillipa. Saddling La Gringa: Major Themes in the Works of Latina Writers. Ed. Ilan Stavans. Westport: Greenwood Press, 2008, p. 3-13.

MADELLA, Thayse. "Woman Hollering Creek" and “Never Marrya Mexican”: the role of the familia/family in the short stories by Sandra Cisneros. In:TUMOLO, Celso Henrique Soufen; BECK, Magali Sperling; COULTHARD, Malcolm. Echoes: Reflections on Language and Literature. Florianópolis: Ufsc, 2014. p. 95-106. Disponível em: http:// ppgi.posgrad.ufsc.br/files/2014/o9/echoes-reflections-on-language-and-literature. pdf. Acesso em: 21 dez. 2017. 
NARVAZ, Martha Giudice; KOLLER, Sílvia Helena. Metodologias feministas e estudos de gênero: articulando pesquisa, clínica e política. Psicol. estud., Maringá , v. 11, n. 3, p. 647-654, Dec. 2006.

NEGRÃO, T. Feminismo no plural. Em M. Tiburi, M. M. Menezes \& E. Eggert (Orgs.), As mulheres e a filosofia (pp. 271-280). São Leopoldo: UNISINOS, 2002.

PINTO, Céli Regina Jardim. Feminismo, história e poder. Revista Sociologia e Politica, Curitiba, v. 18, n. 36, p.15-23, jun. 2010. Disponível em: http://flacso.org.br/ files/2016/10/o3.pdf. Acesso em: 19 dez. 2017.

SAFFIOTI, Heleieth B. Feminismos e seus frutos no Brasil. In: SADER, Emir (Org.). Movimentos sociais na transição democrática. São Paulo: Cortez, 1986.

SANDOVAL, Anna Marie. Toward a Latina Feminism of the Americas: Repression and Resistance in Chicana and Mexicana Literature. Austin: University of Texas Press, 2008.

SCHNEIDER, Liane. "Contando estórias feministas" e a reconstrução do feminismo recente. Estudos Feministas, v. 17, n. 1, 2009.

WALTER, Roland. Multitransintercultura: literatura, teoria pós-colonial e ecocrítica. In: SEDYCIAS, João et al. Repensando a teoria literária contemporânea. Recife: Editora UFPE, p. 605-659, 2015.

Recebido: 18.04.2018

Aceito: 15.10 .2018 